\title{
The Sources of Economic Growth in Sub-Saharan African IDB Member Countries
}

\author{
Nosratollah Nafar \\ Islamic Development Bank, Jeddah, Saudi Arabia
}

\begin{abstract}
The economic growth in Sub-Sahara African (SSA) IDB member countries has been encouraging over the last decade; however, it is still not high enough to enable these countries to overcome the persistent poverty. There is thus a need to raise substantially real GDP growth rates on a sustained basis, both through the productivity channel and factor accumulation such as labor and capital. This study focuses on "the source of economic growth in SSA IDB member countries" with the objective of identifying the main driving factors of economic growth in the region using the growth accounting framework and extending the existing analysis both by country and time coverage. The paper is expected to be useful for the policymakers in the region to have a clear picture on the main sources of growth, and thus help them in identifying strategic reform areas of intervention in line with the most binding factors of growth. The data used in this study cover 20 Sub-Sahara African countries covering the period 1990-2012. The data set includes real GDP, labor force, and capital stock. The source of data is the various version of the World Economic Outlook, IMF. Capital stock is estimated using perpetual inventory method and the base year is 1970. In estimating growth accounting model, a translog production function is applied using panel data and random effects model. Empirical results show that the capital accumulation is the most important individual factor in GDP growth (52\%) followed by workforce accumulation (39\%) while total factor productivity (TFP) accounts for meagre $8 \%$. This suggests that, on average, real GDP growth in Sub-Sahara African countries was driven primarily by factor accumulation with a low level of TFP. In addition, the elasticity of labor was lower than that of capital indicating that the labor played very little role in GDP growth most likely due to unskilled labor force or mismatch of labor skills with the production process. Furthermore, this also adversely affects both the TFP growth and the share of capital growth to the GDP growth. The results indicate that the critical constraint to the economic growth appears to be poor labor skills that lead to both low labor productivity and under-utilization of capital stock.
\end{abstract}

Keywords: sustainable economic growth, total factor productivity, factor accumulation, translog production function, perpetual inventory method, random effects model

\section{Introduction}

With the increasing recognition that productivity is the key to sustained economic growth, measuring productivity is becoming important to economists and policy makers alike. The accurate measurement of

Nosratollah Nafar, Ph.D., lead economist, Economic Research and Policy Department, Islamic Development Bank, Jeddah Saudi Arabia.

Correspondence concerning this article should be addressed to Nosratollah Nafar, P.O. Box 5925, Jeddah 21432, Kingdom of Saudi Arabia. 
productivity growth plays an important role in providing the information economists need to put forth better policy recommendations for policymakers to make the right decisions. Growth accounting framework is a useful tool to contribute to developing a better understanding of the main sources of economic growth with special focus on productivity, which relates to the efficient utilization of resources (Aghion \& Howitt, 1992).

Many studies have analyzed the relative contribution of factor inputs and productivity to economic growth. In the earlier growth models, investment and savings were considered the main pillars of growth. During the 70 's when the neoclassical models were predominant in the literature, neoclassical economists treated technological change as the main ingredient of growth. Corollary to this view is the belief that growth convergence could be achieved between developed and developing countries over time since capital and technology are mobile across countries. In this growth model, output level and growth depend on the country's resource endowment and the productivity of the factors of production (TFP). Since then, the empirical research in this area followed two different strands. One strand is reported by Solow (1957), which decomposes economic growth in a given economy on factor accumulation and total factor productivity. The other is based on cross-country regressions, with a multitude of explanatory variables. Important contributions in this area are those of Baumol (1986), Barro (1999), Sala-Martin (1997), and Leke, Lund, Roxburgh, and van Wamelen (2010).

Concerning SSA IDB member countries, a number of studies have been conducted to understand the main sources of economic growth in the region with a special focus on productivity and efficient utilization of scarce resources. For example, Islam (1995), Sachs and Warner (1995), and O'Connell and Ndulu (2000) among others used the panel regression framework to estimate the source of economic growth with special focus on productivity. More recently, a bulk of the analyses especially by Ajab (2002); Vivek and Bhundia (2003); Tahari, Ghura, Akitoby, and Aka (2004); Nafar (2007); and Kalio and Mutenyo (2012) point to factor accumulation as the main source of growth in sub-Saharan Africa, with the minor contribution of TFP to economic growth. Although the recent pickup in economic growth in SSA IDB member countries has been encouraging, it is still not high enough to enable these countries to make a real dent in the pervasive poverty. There is thus a need to raise substantially real GDP growth rates on a sustained basis, both through the productivity channel and factor accumulation such as labor and capital. This study focuses on "the source of economic growth in SSA IDB member countries" with the objective of identifying the main driving factors of economic growth in the region using the growth accounting framework and extending the existing analysis both by country and time coverage. The paper is expected to be useful for the policymakers in the region to have a clear picture on the main sources of growth, and thus help them in identifying strategic reform areas of intervention in line with the most binding factors of growth. The paper is organized as follows. Section 2 attempts to overview the economic growth of SSA countries. In Section 3, the sources of economic growth and the contribution of productivity and related production factors are explained. Estimation and empirical analysis of growth accounting model are presented in Section 4. Section 5 provides concluding remarks and presents recommendations of the paper.

\section{Economic Growth-Some Initial Considerations}

GDP shows the ability of the country to produce more wealth for its citizens over a specified period. In Figure 1, the trend of real GDP growth for three groups, namely, developing countries, SSA IDB member countries, and the world over a 23 years period from 1990 to 2012 is presented. Over the period of 1996-2004, 
the growth rates of real GDP of the SSA IDB member countries have consistently posted a higher rate as compared to the growth rates of the other groups. For the period from 2007 to 2012, SSA countries have consistently recorded a higher growth rate as compared to those in world; but lower than those in developing countries. For the three years from 1992 to 1995, the growth rates of the SSA IDB member countries have been lower than that in other groups. Over 2007-2009, all three groups experienced significant decline in the growth rate of real GDP due to the financial crisis. Table 1 presents the mean, standard deviation, and the coefficient of variations $^{1}$, for the three groups, over 1990-2012. These summary statistics show that, over the recent 23 years, the average growth rates of real GDP of SSA countries were higher as compared to that in other groups. The coefficient of variation indicates that the volatility in the growth rates of SSA countries is the highest among the three groups. While SSA countries have experienced the highest economic growth, they recorded the lowest growth of real GDP per capita over the period of study.

Table 1

The Summary Statistics of GDP Growth

\begin{tabular}{llll}
\hline & Mean & Standard deviation & Coefficient of variation \\
\hline Developing countries & 5.1 & 1.88 & 0.37 \\
SSA IDB MCs & 5.2 & 2.56 & 0.49 \\
World & 3.5 & 1.32 & 0.38 \\
\hline
\end{tabular}

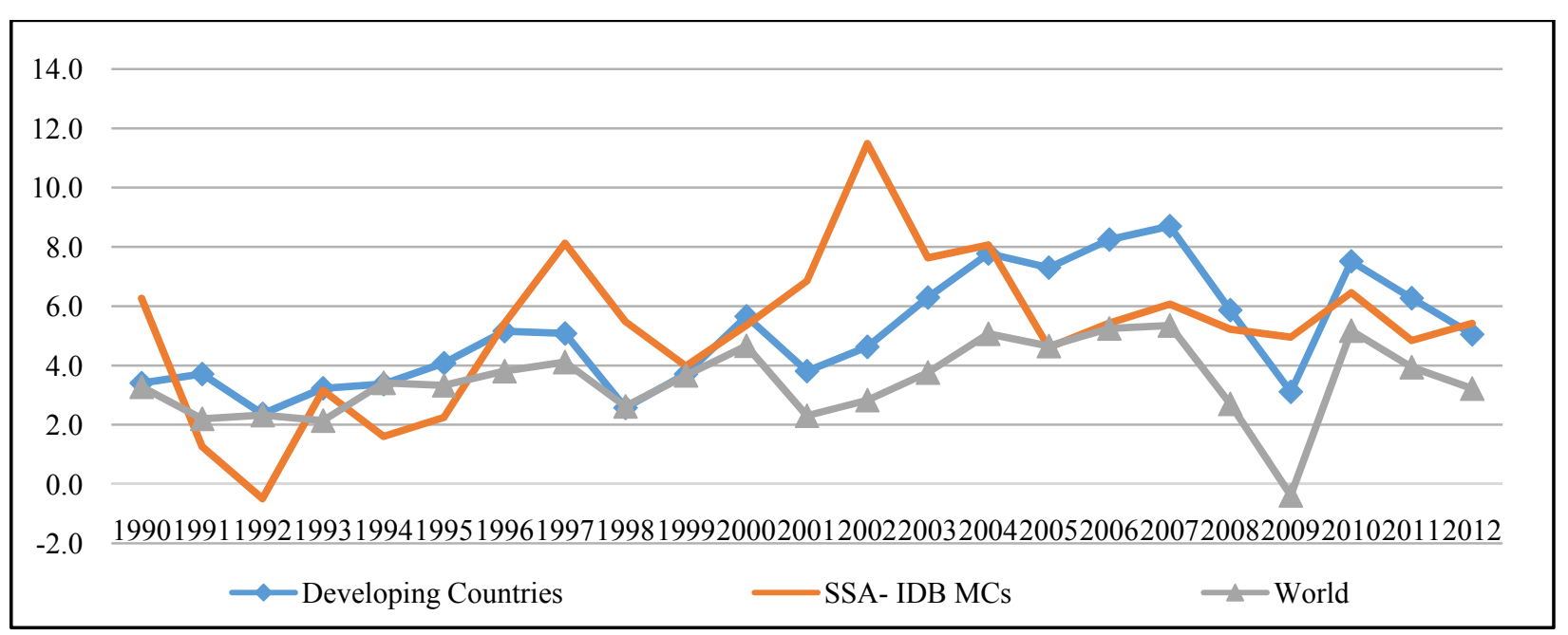

Figure 1. GDP growth, 1990-2012.

In discussing the trends in the growth of real per capita income, it is equally important to examine comparative population growth trends. After all, increasing growth population rates eat away or the gains obtained from economic growth are spread thin over a growing population. Population has both positive and negative interaction with economic growth and development. The distribution of the population by age also plays an important role in economic growth. The high rates of population growth lead to a younger population, and then on to high birth rates, and finally, high labor force for looking for job. This creates an "echo effect" that may influence development running into an immediate difficulty, thus makes it hard to sustain growth in GDP per capita.

\footnotetext{
1 The coefficient of variation is defined as the standard deviation adjusted around the mean of the data. It measures the relative stability of the data.
} 


\section{Sources of Economic Growth}

The objective of economic policy is to improve the quality of life and welfare of citizens, however, it will primarily be dependent on the amounts and types of capital and labor that are invested, and how they are utilized for production. The enormous cross-country differences in economic development and growth have led to research interest in the determinants of economic growth. Generally, three main competing explanations exist with regards to production influencing economic growth. These are capital accumulation, both physical and intangible (knowledge), labor growth, and the pace of technical progress or TFP. Increases in "factors of production" enable an economy to produce more goods and services and therefore the long-run expansion of the economy's ability to produce output. Economic growth however, is made possible not only by increasing the quantity of the economy's resources, but also by increasing their quality. In fact, output growth over time results from accumulation of factors of production and productivity growth. The attribution of output level and growth to factors and productivity is done by using production functions mapping factors into output: what is not accounted for by factors of production as estimated by the production function is attributed to productivity. Let's have the production function as follows:

$$
Y=A F(K, L)
$$

where $Y$ is output, $K$ is capital, and $L$ is labor. $A$ is TFP (Increases in $A$ shifts up the entire production function). It is assumed that the production function yields the maximum output for an arbitrary input vector. Hence, this specifically excludes the possibility of the existence of technical inefficiency. The production function is expected to have the properties of monotonicity, convexity, essentialness and non-negativeness of inputs, and non-emptiness of output, and it is assumed to be continuous everywhere and twice-continuously differentiable (for details see Chambers, 1988, pp. 7-18). Any changes in $Y$ can be due to the changes of $A, K$, or $L$. Therefore, equation (2) is obtained by taking differentiating form (1)

$$
\begin{gathered}
\Delta Y=\Delta A \times F+[A \times(d F / d K) \times \Delta K+A(d F / d L) \times \Delta L] \\
\Delta Y=\Delta A \times F+[M P K \times \Delta K+M P L \times \Delta L]
\end{gathered}
$$

By dividing equation (2) to $Y$, expression (3) is gotten:

$$
\begin{gathered}
\Delta Y / Y=(\Delta A \times F / A \times F)+[(M P K \times \Delta K) / Y] \times K / K+[(M P L \times \Delta L) Y] \times L / L] \\
\Delta Y / Y=(\Delta A / A)+[(M P K \times \Delta K) / Y+(M P L \times \Delta L) Y] \\
\Delta Y / Y=(\Delta A / A)+[(M P K \times \Delta K) / Y] \times K / K+[(M P L \times \Delta L) Y] \times L / L \\
\Delta Y / Y=(\Delta A / A)+[(M P K \times K) / Y] \times \Delta K / K+[(M P L \times L) \times Y] \Delta L / L \\
\Delta Y / Y=(\Delta A / A)+\alpha \Delta K / K+(1-\alpha) \Delta L / L
\end{gathered}
$$

Finally, "Growth Accounting Formula" (expression 4) is gained by applying some mathematical rules.

$$
\% \Delta A=\% \Delta Y-\alpha \% \Delta K-(1-\alpha) \% \Delta L
$$

where, $\% \Delta A$ is total factor productivity growth, $\% \Delta Y$ is GDP growth, $\alpha \% \Delta K$ is elasticity of capital times capital growth and finally, $(1-\alpha) \% \Delta L$ is the elasticity of labor times labor growth. The expression (4) has two assumptions: (i) income distribution: $(M P K \times K) / Y$ equals capital share; $(M P L \times L) Y$ equals labor share; and (ii) constant returns to scale (Euler's Theorem) indicating that capital share plus labor share equals one.

\section{Estimation and Empirical Results}

\section{Estimation}

Many different function forms have been used for the econometric estimation of productivity growth. The 
choice among different functional forms is generally based on the type of analysis to be carried out. In this study, a production function approach is applied. The main advantages with production function are that it does not require information on prices and it allows for non-constant returns to scale. It has several desirable properties such as positive marginal product of inputs, non-emptiness of output, symmetry, monotonicity, and convexity. In addition, the production function is assumed continuous at any point and twice continuously differentiable. Practically, a translog production function, which is a generalization of the Cobb-Douglas functional form is used. The Cobb-Douglas form is restrictive in terms of the implicit substitution assumptions: elasticities of substitution among all inputs are one and shares of the inputs are constant. Extending the Cobb-Douglas to the translog function enables these constraints to be relaxed because cross-effects between inputs are recognized and therefore more complex substitution patterns can then be captured. The translog production function can be written as:

$$
Y_{i t}=\beta_{0}+\beta_{l} L_{i t}+\beta_{k} K_{i t}+1 / 2\left[\beta_{11}\left(L_{i t}\right)^{2}+\beta_{k k}\left(K_{i t}\right)^{2}+\beta_{l k} L_{i t} K_{i t}\right]+\varepsilon_{i t}
$$

where $Y$ is the log of GDP, $L$ and $K$ are the $\log$ of labor and capital, the $\beta s$ are the unknown parameters and $\varepsilon_{i t}$ is error term composed of a time-invariant country-specific effects $\left(v_{i}\right)$ and a statistical noise $\left(u_{i t}\right)$ component. The assumptions made on error components are as follows:

(1) $v_{i}$-i. i. d. $N\left(0, \sigma^{2}{ }_{v i}\right)$

(2) $u_{i t}-i . i . d . N\left(0, \sigma_{u}^{2}\right)$, uncorrelated across countries over time,

(3) $v_{i}$ and $u_{i t}$ are independent of each other and of the explanatory variables.

Given the estimated parameters in equation (5), the elestisities of labor and capital are defined as the percentage change in GDP due to an increment of labor and capital. Thus,

$$
\begin{aligned}
& E L_{i t}=\partial Y_{i t} / \partial L_{i t}=\beta_{l}+\beta_{l l} L_{i t}+1 / 2 \beta_{l k} K_{i t} \\
& E K_{i t}=\partial Y_{i t} / \partial K_{i t}=\beta_{k}+\beta_{k k} K_{i t}+1 / 2 \beta_{l k} L_{i t}
\end{aligned}
$$

Then total factor productivity growth is measured by expression (8)

$$
T F P_{i t}=\Delta \mathrm{GDP}_{i t}-E K_{i t} \Delta K_{i t}-E L_{i t} \Delta L_{i t}
$$

where $\Delta \mathrm{GDP}_{i t}$ is economic growth, $E K_{i t} \Delta K_{i t}$ is the contribution of capital growth on economic growth, and $E L_{i t} \Delta L_{i t}$ is the contribution of labor growth to economic growth.

\section{Empirical Results}

The data used in this study cover 20 IDB member countries from SSA covering the period 1990-2012. The data set includes real GDP, labor force, and capital stock. The source of data is the various version of the World Economic Outlook, IMF. The most problematic input to measure is capital. The perpetual inventory method is used to estimate capital stock and the base year is 1970. The method assumes that (a) capital services never reach zero so every unit of investment is perpetually a part of the stock of capital; (b) the capital in the country is in full capacity utilization (the machine runs at full tilt until it dies); and (c) linear depreciation (e.g. 4.5\% of the initial capital stock in its time period). The parameter estimates of the translog production function (5) using random effects model are reported in Table 2. Empirical results show that the capital and labor elasticities are 0.35 and 0.56 , respectively. These parameters can be interpreted as follows: a one percent increase in capital could raise the real GDP by 0.35 percent while a one percent increase in labor can be expected to increase the real GDP by 0.56 percent. This indicates that capital is relatively less productive as compared to the labor. In fact, the argument can be extended to suggest that future increase in capital productivity will be constrained by the unproductive labor force, unless labor skills are enhanced. 
Considering the estimation of the growth accounting model, aggregate capital accumulation is the most important individual factor in explaining GDP growth (52\%) followed by workforce accumulation (39\%) while TFP accounts for meagre $8 \%$. The sources of economic growth in SSA IDB member countries are presented in Figure 2 below. The GDP growth rate, at the aggregate level, depicts relatively large fluctuation ranging from $-0.33 \%$ in 1992 to a high of $6.6 \%$ in 2001 . The share of labor growth in GDP growth was constant around $1.67 \%$ over the period of the study. This indicates that the growth in labor force did not significantly contribute to the economic growth rate at the aggregate level. Moreover, the contribution of capital to the economic growth is increasing indicating that the real GDP growth in SSA IDB member countries was driven primarily by capital accumulation with a moderate level of labor growth. The trend of capital growth shows that SSA countries put relatively greater efforts to increase the production capacity through higher capital accumulation. However, it appears that such an investment program simply by-passed the required skill enhancement of labor for more effective utilization of the technology and production equipments.

Table 2

Generalized Least Squares Parameter Estimates

\begin{tabular}{llllll}
\hline Parameter & Estimate & Std. error & Parameter & Estimate & Std. error \\
\hline$\beta_{0}$ & -12.9 & 1.34 & $\beta_{\mathrm{kk}}$ & 0.174 & 0.03 \\
$\beta_{\mathrm{k}}$ & 1.72 & 0.25 & $\beta_{\mathrm{ll}}$ & -0.029 & 0.03 \\
$\beta_{\mathrm{L}}$ & 1.51 & 0.40 & $\beta_{\mathrm{kl}}$ & -0.289 & 0.04 \\
\hline
\end{tabular}

Notes. Adj- $\mathrm{R}^{2}=0.58$, Labor elasticity $=0.56$, Capital elasticity $=0.35$.

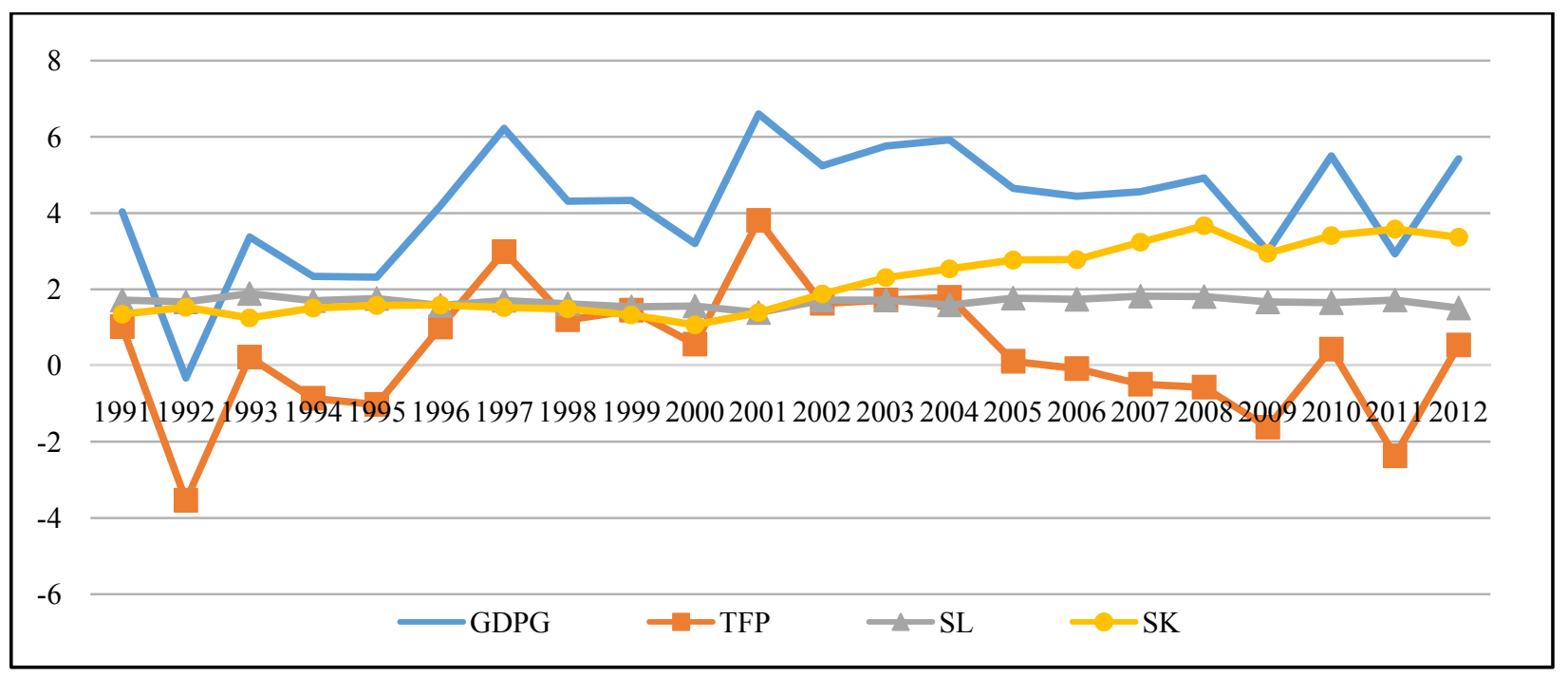

Figure 2. The sources of economic growth in Sub-Sahara African countries.

As clear from Figure 2, the gap among the growth rates of TFP, share of labor, and share of capital has been widening since 2004 as compared to the earlier period 1992 to 2003. This indicates that SSA IDB member countries have been paying more attention on factor accumulation particularly, capital rather than enhancing productivity. The time pattern of TFP shows significant fluctuation over the period of the study. It increased from minimum 5\% in 1992 to its maximum level at 4\% in 2001 and then started to decrease. The contribution of TFP to economic growth of SSA countries has been negative since 2006. The large fluctuation of TFP over the period of 2008-2012 could be attributed to the impact of global financial crisis. 
The sources of economic growth at country level are presented in Table 3. In terms of economic growth, Sudan, Mozambique, Uganda, Chad, and Nigeria are the top five countries, whereas Djibouti, Sierra Leone, and Guinea Bissau recorded the lowest GDP growth over the period of the study. Of the 20 countries from the region for which data are available, nine countries rank above the average economic growth of the region (4.2\%) while the remaining 11 have experienced below the overall average.

As far as the share of labour growth to GDP growth is concerned, the computed values of the index show that the top five countries are Niger, Mali, Benin, Sudan, and Chad, whereas the countries with the lowest values of the index are Togo and Sierra Leone. The ranking of member countries in terms of the share of the capital growth to GDP growth index shows that Nigeria is at the top followed by Sierra Leone, whereas member countries with the lowest rankings are Guinea Bissau and Cameroon. Lastly, in terms of TFP growth index, Mozambique, Burkina Faso, and Sudan experienced the highest TFP growth. Five member countries in the region, on average, recorded negative TFP growth over the period of the study. These countries are Côte d'Ivoire, Gabon, Sierra Leone, Djibouti, Mauritania, and Niger.

Table 3

Sources of Economic Growth in Sub-Sahara African Countries

\begin{tabular}{llllllllll}
\hline Country & $\begin{array}{l}\text { GDP } \\
\text { growth }\end{array}$ & $\begin{array}{l}\text { TFP } \\
\text { growth }\end{array}$ & $\begin{array}{l}\text { Share of } \\
\text { labor } \\
\text { growth }\end{array}$ & $\begin{array}{l}\text { Share of } \\
\text { capital } \\
\text { growth }\end{array}$ & Country & $\begin{array}{l}\text { GDP } \\
\text { growth }\end{array}$ & $\begin{array}{l}\text { TFP } \\
\text { growth }\end{array}$ & $\begin{array}{l}\text { Share of } \\
\text { labor } \\
\text { growth }\end{array}$ & $\begin{array}{l}\text { Share of } \\
\text { capital } \\
\text { growth }\end{array}$ \\
\hline Benin & 4.24 & 0.26 & 1.91 & 2.07 & Burkina Faso & 5.77 & 2.37 & 1.66 & 1.75 \\
Cameroon & 2.57 & 0.20 & 1.73 & 0.64 & Chad & 6.30 & 0.55 & 1.79 & 3.95 \\
Côte d'Ivoire & 2.28 & -0.62 & 1.38 & 1.51 & Djibouti & 1.67 & -1.36 & 1.67 & 1.42 \\
Gabon & 2.01 & -0.58 & 1.41 & 1.18 & Gambia & 3.75 & 1.10 & 1.72 & 0.93 \\
Guinea & 3.36 & 0.96 & 1.70 & 0.69 & Guinea-Bissau & 1.91 & 0.16 & 1.52 & 0.23 \\
Mali & 4.37 & 0.21 & 2.20 & 1.85 & Mauritania & 3.56 & -0.59 & 2.11 & 2.05 \\
Mozambique & 7.33 & 2.96 & 1.49 & 2.88 & Niger & 3.57 & -1.78 & 2.24 & 3.11 \\
Nigeria & 6.18 & 1.60 & 1.42 & 3.16 & Senegal & 3.55 & -0.41 & 1.72 & 2.24 \\
Sierra Leone & 1.85 & -1.94 & 1.21 & 2.58 & Sudan & 9.37 & 2.00 & 1.79 & 5.59 \\
Togo & 4.24 & 1.20 & 1.19 & 1.85 & Uganda & 6.60 & 0.84 & 1.67 & 4.08 \\
Mean & 4.22 & 0.36 & 1.67 & 2.19 & & & & &
\end{tabular}

\section{Conclusions and Recommendations}

Productivity is a crucial factor in production performance and in raising living standards because more real income improves people's ability to purchase goods and services, and contribute to social and environmental programs. There is no doubt that low productivity growth is one of important issues, which could threaten significantly sustainable economic growth in SSA IDB member countries.

This paper examined the sources of economic growth in SSA IDB member countries using growth accounting framework. The results of the analysis show that average real GDP growth in the region during the period of the study was driven primarily by factor accumulation with little role for TFP. The empirical results also show that the central thrust of economic growth came from growth in the capital stock while the share of the labor in economic growth has been sluggish. Specifically, aggregate capital accumulation is the most important individual factor in explaining GDP growth (52\%) followed by workforce accumulation (39\%) while TFP accounts for meagre $8 \%$. This suggests that, on average, real GDP growth in SSA IDB member countries was driven primarily by factor accumulation with a very low level of TFP. The trend of capital growth shows 
that these countries put relatively greater efforts to increase the production capacity through higher capital accumulation rather than enhancing TFP. The time pattern of TFP shows significant fluctuation over the period of the study with negative contribution to economic growth of these countries since 2006. In the light of the empirical findings of this paper, the IDB may consider the following major recommendations:

(1) For the countries, which are weak in terms of capital contribution to GDP growth, the first priority is to adopt reforms on fast track basis to remove major obstacles to doing business with a special focus on attracting more investment particularly, FDI. This will help them to overcome resource constraints and advance their technological development.

(2) For the countries, which are weak in terms of human resource contribution to GDP growth, the top priority is to implement reforms on fast track basis to ensure linkages between human development and economic growth. They may enhance productivity through education reforms aimed at increasing adult education, on-the-job training, linking of future skill-needs to the education system, and providing more vocational training especially to support the skill requirements of the small and medium enterprises.

(3) Using the results of other studies such as Collier and Gunning (1997), Thirlwall (2006), and Nafar (2014) as a guide, the paper argues that the factors that can positively influence TFP growth in sub-Saharan Africa include good quality institutions, human capital development, a favorable macroeconomic policy environment, trade liberalization, and diversification of the economic base from agriculture to manufacturing and services.

\section{References}

Leke, A., Lund, S., Roxburgh, C., \& van Wamelen, A. (2010). What's driving Africa's growth. McKinsy \& Company. Aghion, P., \& Howitt, P. (1992). A model of growth through creative destruction. Econometrica, 60(2), 323-351.

Ajab, A. A. (2002). An examination of the sources of economic growth in Cameroon. African Economic Research Consortium Research Paper 116.

Kalio, A. M., \& Mutenyo, K. J. (2012). Analysis of economic growth in Kenya: Growth accounting and total factor productivity. Department of Economics, Egerton University, Kenya.

Vivek, B. A., \& Bhundia, A. J. (2003). Potential output and total factor productivity growth in post-apartheid South Africa. IMF Working Paper 03/178, IMF.

Barro, R. J. (1999). Economic growth in a cross section of countries. Quarterly Journal of Economics, 106(2), 407-433.

Baumol, W. J. (1986). Productivity growth, convergence, and welfare: What the long-run data show. The American Economic Review, 76(5), 1072-1085.

Chambers, R. G. (1988). Applied production analysis: A dual approach. Cambridge University Press.

Collier, P., \& Gunning, J. W. (1997). Explaining African economic performance. Centre for the Study of African Economies, Working Paper Series. WPS/97/2.

Islam, N. (1995). Growth empirics: A panel data approach. The Quarterly Journal of Economics, 110(4), 1127-1170.

Nafar, N. (2007). Productivity growth in IDB member countries. Islamic Development Bank.

Nafar, N. (2014). Regional economic developments and outlook; Sub Saharan African member countries. Islamic Development Bank.

Connell, O., Stephen, A., \& Ndulu, B. J. (2000). Africa's growth experience: A focus on sources of growth. Retrieved from http://www.swarthmore.edu/SocSci/soconne1/documents/revision2.pdf

Sachs, J. D., \& Warner, A. M. (1995). Sources of slow growth in African economies. Journal of African Economies, 6(3), 335-376.

Sala-Martin, X. X. (1997). I just ran four million regressions. American Economic Review, 87(2), 178-183.

Solow, R. M. (1957). Technical change and the aggregate production function. Review of Economics and Statistics, 39, $312-320$.

Tahari, A., Ghura, D., Akitoby, B., \& Aka, E. B. (2004). Sources of growth in Sub-Saharan Africa. IMF Working Paper No. 176, 1-30.

Thirlwall, A. P. (2006). Growth and development: With special reference to developing economies. Palgrave Macmillan. ISBN $1-4039-9600-8$. 